ЗАХАРОВ Виктор Михайлович - доктор социологических наук, профессор; профессор кафедры социальных технологий и государственной службы, директор Института экономики и управления Белгородского государственного национального исследовательского университета (308015, Россия, г. Белгород, ул. Победы, 85; zakharov@bsu.edu.ru)

БыХТИН Олег Викторович - кандидат социологических наук, доцент; доцент кафедры социальных технологий и государственной службы Института экономики и управления Белгородского государственного национального исследовательского университета (308015, Россия, г. Белгород, ул. Победы, 85; bykhtin@bsu.edu.ru)

ЮРКОВА Ольга Николаевна - кандидат социологических наук, доцент кафедры социальных технологий и государственной службы Института экономики и управления Белгородского государственного национального исследовательского университета (308015, Россия, г. Белгород, ул. Победы, 85; yurkova@bsu.edu.ru)

\title{
ОБОСНОВАНИЕ СИСТЕМЫ ПОКАЗАТЕЛЕЙ, ПОЗВОЛЯЮЩИХ ДИАГНОСТИРОВАТЬ СОСТОЯНИЕ КОНСОЛИДАЦИИ ГОРОДСКИХ СООБЩЕСТВ В РОССИИ
}

Аннотация. В статье предпринята попытка обоснования системы показателей, позволяющих диагностировать состояние консолидации городских сообществ в современном российском обществе. Авторы статьи исходят из того, что консолидация представляет собой регулируемый и саморегулируемый процесс, требующий качественного анализа и прогнозирования. По мнению авторов, процесс консолидации городских сообществ является противоречивым, нестабильным, поэтому показатели должны учитывать все возможности и тенденции, которые зачастую имеют взаимоисключающий характер. $B$ результате предлагаются шесть групп показателей консолидации городских сообществ.

Ключевые слова: консолидация, городские сообщества, показатели, солидарное общество, городская идентичность

$\Pi$ роцесс консолидации городских сообществ требует качественного анализа, прогнозирования и регулирования, позволяющего достичь целей и минимизировать неизбежные негативные следствия.

Консолидация городских сообществ представляет собой регулируемый и саморегулируемый процесс. Регулирование процесса консолидации связано с приведением его в состояние нормы посредством внедрения в него определенных регуляторов: норм, правил, целей, связей. Однако на практике мы имеем постоянные отклонения, которые вызваны комплексом причин. Зачастую сама идея возможности консолидации отвергается в силу достаточно выраженной дифференциации общества, где зачастую невозможно достичь некого единения.

Кроме того, в любом обществе нарастание неравенства рассматривается как негативный процесс, сопровождающийся возникновением социальной напряженности и значительных рисков для устойчивого экономического и общественного развития. Происходит раскол городских сообществ, и возникает отчужденность от муниципальных институтов власти, что порождает абсолютно негативное отношение населения к взаимодействию с органами власти в целях достижения общественно значимых целей. Для того чтобы минимизировать влияние вышеуказанных причин, необходимы точные показатели, на основе анализа которых можно соотнести норму и девиацию, принять эффективные решения. Следует учитывать, что консолидация явля- 
ется сознательным и добровольно реализуемым процессом, который нельзя навязать «сверху», используя лишь административные ресурсы управления. Перспективы консолидации в значительной степени определяются установками и ориентациями горожан. Одним из важнейших индикаторов в данном случае будет выступать доверие.

Показатель обобщенного доверия окружающим не связан напрямую с реальной общественной активностью. Он скорее отражает общую атмосферу в обществе, уровень открытости и доброжелательности граждан, однако выступает неким гарантом качественных межгрупповых отношений и сотрудничества.

Чтобы мотивировать население городских сообществ к участию в процессе консолидации, необходимо в первую очередь релевантно представлять эти установки. Следует понимать, что в ходе консолидации с неизбежностью возникает сопротивление. Наряду с нарастанием недоверия к власти, в обществе происходит расслоение в отношении понимания социальных норм, общественных противоречий, которые зачастую сопровождаются усилением негативных явлений. Состояние нестабильности и чувства отчуждения формируют в обществе не только социальную аномию, но и ряд других негативных тенденций.

Необходимость диагностики процесса консолидации определяется:

- важностью поиска показателей, на основе анализа которых можно соотнести норму и девиацию, принять эффективные решения по минимизации отклонений;

- значимостью задачи мотивации населения городских сообществ к участию в процессе консолидации;

- важностью преодоления неизбежного сопротивления консолидационным тенденциям.

Так, Л.Я. Дятченко указывал, что «любое нововведение, если оно только не ограничивается жизненным пространством отдельного человека, затрагивает так или иначе и других людей, вызывает к себе их определенное отношение: содействующее или сочувствующее, восторженное или скептическое. От этого отношения зависит во многом успех нововведения. Поэтому важно обеспечить его положительную направленность, что подразумевает, в свою очередь, знание и учет тех причин, по которым люди отторгают нововведения. Допускается возможность повлиять на эти причины в сторону их ослабления или устранения» [Дятченко 1993: 225]. Для этого следует четко определить диспозиции противников процессов консолидации.

Процесс консолидации городских сообществ имеет последовательные этапы, включающие обоснование идеи консолидации в мышлении горожан посредством продвижения ценностей солидарного общества, развитие технологий мотивации населения к коллективным действиям, формирование межличностных коммуникаций и коммуникаций «власть - общество».

Этап формирования городской идентичности представляет собой определенный момент, при котором происходит отождествление, соотнесение субъектом себя с городским сообществом, к которому он непосредственно принадлежит. На данном этапе первоочередными выступают когнитивный, эмоциональный и ценностный компоненты, т.е. те субъективные динамичные факторы, которые подлежат оценке и измерению в ходе исследования. На данном этапе оценки требует степень сформированности идентичности и факторы, которые определяют идентификацию.

Этап ценностной селекции и ценностной ориентации. Специфика указанного этапа заключается в том, что процесс консолидации городского сообщества опирается на ценности и установки субъекта в определенный период времени. 
Он предполагает выявление степени сформированности ценностей консолидации. В данном случае следует проследить мотивы и стимулы поведения населения городского сообщества, выявить ценностные установки, соответствующие различным группам городских жителей.

Этап установления отношений доверия требует определения уровня межличностного и институционального доверия.

Этап формирования символической солидарности. Оценка ориентирована на установление содержания представлений о сущности солидарности. Здесь следует активно продвигать идею совместного сотрудничества и взаимопомощи в целях решения общегородских проблем.

Этап деятельной консолидации предопределяет оценку типичных консолидационных практик, готовности и способности к их применению.

Диагностика востребована и для того, чтобы отрефлексировать прохождение каждого из указанных этапов.

Консолидацию городского сообщества следует рассматривать как многофакторный, сложный процесс в силу его многогранности и разнонаправленности. Трудности оценки в данном случае усугубляются его многослойностью. Можно говорить о социальной, межпоколенной, межнациональной, гендерной, профессиональной консолидации. Городская социальная среда формирует специфическую внутренне противоречивую конфигурацию человеческих взаимоотношений. С одной стороны, наличие большой массы людей, сопряженное с высокой интенсивностью информационных потоков, создает широкие возможности для межличностных контактов, с другой - именно в городе человек нередко наиболее остро ощущает свое одиночество как следствие взаимного отчуждения сограждан, жизнедеятельность которых строится на максимально прагматичных основаниях.

Характеризуя специфику городской жизни, Л.Д. Хлевной приводит мнение социального психолога С. Милграйма, который утверждал, что для городских поведенческих стандартов типично «полное пренебрежение к нуждам, интересам и требованиям тех людей, которых человек не считает непосредственно связанными с удовлетворением его личных потребностей» [Хлевной 2004: 26].

Любой многомерный процесс требует дифференцированных технологий оценки, а динамичность и нестабильность - их гибкости. Многоуровневость консолидации как процесса предполагает, что показатели должны быть соотнесены с процессами, протекающими как на уровне города в целом, так и на уровне его отдельных территорий и групп населений.

Показатель - это качественная или количественная характеристика отдельных свойств и состояний социальных объектов и процессов, совокупность которых отражает их особенности в статике и динамике. Следует разграничить понятия «показатель» и «индикатор». Согласно И.В. Бестужеву-Ладе, «показатель - это операционная характеристика социально значимого явления или процесса, которая отражает его свойства, связи или отношения и является одновременно инструментом измерения последних. В широком смысле показатель - это любая потенциально или актуально поддающаяся эмпирической проверке характеристика объекта» [Бестужев-Лада, Наместникова 2002: 32]. Индикатор же выступает структурным элементом показателя и представляет собой доступные наблюдению и измерению характеристики изучаемого социального объекта. Таким образом, показатель - это критерий или признак, на основании которого производится оценка или измерение процесса, а индикатор - характеристика, которая измеряется и количественно отражает состояние объекта.

К показателям оценки процесса консолидации предъявляется ряд требований. 
1. Конкретность. Показатель должен быть однозначным и понятным, четко сформулированным, отражающим реальные характеристики и свойства предмета исследования, он должен иметь привязку к определенному времени, месту и отвечать другим условиям, не позволяющим трактовать его двояко.

2. Адекватность объекту. Показатель должен быть релевантен измеряемому объекту (иначе говоря, необходимо измерять именно то, что планируется измерить, не отвлекаясь на оценку процессов общего характера, лишь косвенно связанных с объектом), учитывать особенности восприятия свойств объектов.

3. Операционализируемость. Показатель должен быть взаимоувязан с теоретическими понятиями и эмпирическими наблюдениями и интерпретирован с их учетом.

4. Реалистичность. Показатель должен отражать возможность построения на его основе эмпирических индикаторов, доступных для наблюдения и фиксации.

В основу разработки системы показателей оценки консолидации городских сообществ должны быть положены следующие принципы разработки системы показателей:

1) принцип объективности, который обеспечивается многообразием объектов оценки (диспозиции, условия, мотивы) и, соответственно, соотнесением с ними показателей, их выстраиванием с учетом дополняемости. В таком случае возникает возможность сравнить показатели. В рамках городского пространства в условиях фактической разнородности информации могут возникать ситуации, позволяющие субъективировать показатели, а зачастую и вовсе сфальсифицировать. Показатели должны обеспечивать получение информации о реальном состоянии объекта, а не его субъективной интерпретации;

2) принцип научности, который является, во-первых, продолжением предыдущего принципа и предполагает отсутствие изначальной убежденности в правоте конкретных идеологий и политических решений; во-вторых, исходит из постоянной рефлексии по поводу высказываемых суждений и, главное, методов получения и интерпретации информации. Методологическая база исследования должна учитывать имеющиеся в современной социологической и экономической науках теории детерминантов, а в основу выбора методов сбора информации следует положить принципы оптимальности и достаточности;

3) принцип системности, который предполагает изучение феномена развития консолидации городских сообществ и ее динамики в системе причинноследственных связей и иерархии компонентов, таких как субъекты, объекты, взаимосвязи между ними. Особое внимание следует в данном контексте уделять комплексу факторов внешней и внутренней среды, определяющей развитие консолидации городских сообществ;

4) принцип практикоориентированности, который позволяет осуществлять исследование применительно к реализации конкретных целей, состоящих в выявлении конкретных методов. Цель данной регуляции состоит в стимулировании стратегий развития, способствующих успешной реализации развития консолидации городских сообществ и социальной интеграции на мезои макросоциальном уровне, и, напротив, в нивелировании негативистских моделей, ведущих к прогрессирующему ухудшению консолидации городских сообществ;

5) принцип измеримости, который предполагает наличие критериев (измерителей) каждого показателя и возможность их использования.

Нам представляется целесообразным выделить шесть групп показателей консолидации городских сообществ. 
1. Диспозиционные - группа показателей, позволяющих оценить интересы, ценности, цели, мотивы объектов исследования. Эти показатели позволяют определить ценности солидарности применительно к населению городских сообществ, т.е. материальные и нематериальные объекты, которые индивиды, социальные группы, политические сообшества наделяют высокими значениями, определяющими структуру целеполагания. С их помощью определяются сформированность ценностей солидарности, наличие общих консолидирующих интересов, выраженность солидарной мотивации, цели консолидации. Эмпирическими индикаторами ценности солидарности может выступать оценка ощущения справедливости оснований городской жизни - общая нравственная санкция совместной жизни людей, которая отражает предметные представления о должном уровне благосостояния, доступности жизненных благ в обществе.

2. Коммуникативные - группа показателей, определяющих характер межличностных, межгрупповых, институциональных взаимоотношений, удовлетворенность ими. С их помощью определяется удовлетворенность состоянием коммуникаций, готовность к конструктивному взаимодействию. В рамках данной группы показателей следует выявить готовность к сотрудничеству (желание субъекта вступить во взаимодействие для достижения цели или решения задач); межгрупповому и межличностному диалогу (способность субъекта контактировать с другими общностями и группами); взаимопомощи (уровень отзывчивости, желания субъекта оказать необходимую помощь, поддержку).

3. Праксеологические - показатели, отражающие распространенность применения консолидационных практик. С их помощью определяется владение навыками консолидационных практик, владение технологиями конфликтного менеджмента. Они связаны с определением степени распространенности практик сотрудничества (число заключенных договоров о межмуниципальном сотрудничестве), межгруппового и межличностного диалога (число зафиксированных официальных мероприятий в рамках собраний граждан городского сообщества), взаимопомощи (число и частота встреч для решения проблем городских сообществ).

4. Инфраструктурные - группа показателей, определяющих наличие организаций, материальных объектов для развития консолидации городских сообществ. С их помощью определяется сформированность организационной структуры консолидации, наличие ресурсов консолидации. Так, например, эмпирическим индикатором может выступать наличие площадок консолидации - «дружелюбных мест», проектирование и строительство которых осуществляется стимулирующими, а не директивными мерами путем создания благоприятных условий для изменения среды эволюционным путем, но с заданными характеристиками (наличие доступных мест отдыха, планировочных зон в городе, наличие общественно-деловой инфраструктуры, эффективность органов власти в создании условий, необходимых для формирования качественной городской среды) [Глазычев 2008].

5. Когнитивные - группа показателей, отражающих информированность субъекта о содержании консолидационных процессов. С их помощью определяется уровень информированности о содержании консолидационных процессов - знание, информированность горожан о наличии функционирующих НКО, общественных организаций, деятельность которых направлена на улучшение среды проживания городского сообщества, на создание солидарного общества, а также степень компетентности в отношении проблем консолидации и солидарности (наличие опыта участия в консолида- 
ционных процессах, адекватность представлений о консолидации, наличие представлений о необходимости консолидации, знание технологий консолидации).

С учетом исследовательской проблемы представляется целесообразным выделить особую группу показателей, позволяющих оценить влияние фактора цифровизации на процесс консолидации городских сообществ.

6. Информационно-технологические - группа показателей, позволяющих оценить влияние фактора цифровизации на процесс консолидации городских сообществ. С их помощью определяется полнота и адекватность представлений о цифровизации городского пространства. Эмпирическими индикаторами могут выступать уровень информированности (показатель уровня знаний о процессе консолидации городских сообществ), характер отношения к цифровизации (рациональный и аффективный) - отражение взглядов респондентов на фактор цифровизации в процессе консолидации городских сообществ, степень адекватности представлений о цифровизации и ее последствиях (показатель соответствия ожиданиям и ситуативным требованиям фактора цифровизации и оценка ее предполагаемых последствий), рефлексия опыта применения цифровых технологий (показатель применения цифровых технологий в процессах деятельности и оценка опыта их использования).

Таким образом, важно понимать, что процесс консолидации городских сообществ является противоречивым, нестабильным, поэтому показатели должны учитывать все возможности и тенденции, которые зачастую имеют взаимоисключающий характер.

Консолидация - процесс не линейный, он предполагает состояние бифуркации, где в любой из точек возможно отклонение от запланированных сценариев. Это предопределяет дифференциацию показателей, обеспечивающую учет вариативности процесса.

В ходе консолидации сочетаются объективные и субъективные тенденции, что должно учитываться при построении показателей. Объективные показатели определяются с помощью официальных статистических данных, но субъективные отражают диспозиции участников консолидационного процесса. Отсюда важна их взаимодополняемость.

Динамичность городской среды и процессов консолидации общества предопределяет необходимость постоянной корректировки показателей согласно происходящим изменениям. Кроме того, необходимо учитывать и многофакторность процесса.

Разработка показателей предполагает теоретическое осмысление сущности изучаемых явлений, а создание системы показателей опирается на выявление объективных закономерностей общественного развития и четкое представление о структуре и уровнях соответствующих социальных объектов. Таким образом, показатели являются итогами глубокого изучения социальных явлений, благодаря чему те или иные их характеристики могут обоснованно рассматриваться как свидетельства целостного состояния социального объекта или процесса.

Исследование выполнено за счет гранта Российского научного фонда № 21-18-00150.

\section{Список литературы}

Бестужев-Лада И.В., Наместникова Г.А. 2002. Социальное прогнозирование : курс лекций. М.: Педагогическое общество России. 386 с.

Глазычев В.Л. 2008. Урбанистика. М.: Европа. 220 с. 
Дятченко Л.Я. 1993. Социальные технологии в управлении общественными процессами. М.; Белгород: Центр социальных технологий. 343 с.

Хлевной Л.Д. 2004. Управление социальной сферой крупнейшего города в современной России: дис. ... к.соц.н. Краснодар. 161 с.

ZAKHAROV Viktor Mikhailovich, Dr.Sci. (Soc.), Professor; Professor of the Chair of Social Technologies and Public Service, Director of the Institute of Economics and Management, Belgorod National Research University (85 Pobedy St, Belgorod, Russia,308015; zakharov@bsu.edu.ru)

BYKHTIN Oleg Viktorovich, Cand.Sci. (Soc.), Associate Professor; Associate Professor of the Chair of Social Technologies and Public Service, Institute of Economics and Management, Belgorod National Research University (85 Pobedy St, Belgorod, Russia, 308015; bykhtin @bsu.edu.ru)

YURKOVA Olga Nikolaevna, Cand.Sci. (Soc.), Associate Professor of the Chair of Social Technologies and Public Service, Institute of Economics and Management, Belgorod National Research University (85 Pobedy St, Belgorod, Russia, 308015; yurkova@bsu.edu.ru)

\title{
JUSTIFICATION OF A SYSTEM OF INDICATORS THAT ALLOWS DIAGNOSING THE STATE OF CONSOLIDATION OF URBAN COMMUNITIES IN RUSSIA
}

\begin{abstract}
The article attempts to substantiate the system of indicators that allow diagnosing the state of consolidation of urban communities in modern Russian society. The authors of the article proceed from the assumption that consolidation is a regulated and self-regulatory process that requires qualitative analysis and forecasting. According to the authors, the process of consolidation of urban communities is contradictory, unstable, therefore, indicators should take into account all opportunities and trends, which are often mutually exclusive. As a result, six groups of indicators of the consolidation of urban communities are proposed.
\end{abstract}

Keywords: consolidation, urban communities, indicators, solidarity society, urban identity 